\title{
STXBP1 encephalopathy
}

\section{A neurodevelopmental disorder including epilepsy}

Hannah Stamberger, MD

Marina Nikanorova, MD

Marjolein $\mathrm{H}$. Willemsen, $\mathrm{MD}, \mathrm{PhD}$

Patrizia Accorsi, MD*

Marco Angriman, MD*

Hartmut Baier, MD*

Ira Benkel-Herrenbrueck, MD*

Valérie Benoit, $\mathrm{PhD*}$

Mauro Budetta, MD*

Almuth Caliebe, MD*

Gaetano Cantalupo, MD*

Giuseppe Capovilla, MD*

Gianluca Casara, MD*

Carolina Courage, MD*

Marie Deprez, MD*

Anne Destrée, MD*

Robertino Dilena, MD*

Corrie E. Erasmus, MD, $\mathrm{PhD}^{*}$

Madeleine Fannemel, MD*

Roar Fjær, MD*

Lucio Giordano, MD*

Katherine L. Helbig, MSc*

Henrike O. Heyne, MD*

Joerg Klepper, MD, $\mathrm{PhD}^{*}$

Gerhard J. Kluger, MD, PhD*

Damien Lederer, MD, PhD*

Monica Lodi, MD*

Oliver Maier, MD*

Andreas Merkenschlager, MD*

Nina Michelberger, $M D^{*}$ Carlo Minetti, MD, $\mathrm{PhD}^{*}$

Author list continued on next page

\section{ABSTRACT}

Objective: To give a comprehensive overview of the phenotypic and genetic spectrum of STXBP1 encephalopathy (STXBP1-E) by systematically reviewing newly diagnosed and previously reported patients.

Methods: We recruited newly diagnosed patients with STXBP1 mutations through an international network of clinicians and geneticists. Furthermore, we performed a systematic literature search to review the phenotypes of all previously reported patients.

Results: We describe the phenotypic features of 147 patients with STXBP1-E including 45 previously unreported patients with 33 novel STXBP1 mutations. All patients have intellectual disability (ID), which is mostly severe to profound (88\%). Ninety-five percent of patients have epilepsy. While one-third of patients presented with Ohtahara syndrome (21\%) or West syndrome $(9.5 \%)$, the majority has a nonsyndromic early-onset epilepsy and encephalopathy (53\%) with epileptic spasms or tonic seizures as main seizure type. We found no correlation between severity of seizures and severity of ID or between mutation type and seizure characteristics or cognitive outcome. Neurologic comorbidities including autistic features and movement disorders are frequent. We also report 2 previously unreported adult patients with prominent extrapyramidal features.

Conclusion: De novo STXBP1 mutations are among the most frequent causes of epilepsy and encephalopathy. Most patients have severe to profound ID with little correlation among seizure onset, seizure severity, and the degree of ID. Accordingly, we hypothesize that seizure severity and ID present 2 independent dimensions of the STXBP1-E phenotype. STXBP1-E may be conceptualized as a complex neurodevelopmental disorder rather than a primary epileptic encephalopathy. Neurology ${ }^{\circledR}$ 2016;86:1-9

\section{GLOSSARY}

AED = antiepileptic drugs; EOEE = early-onset epilepsy and encephalopathy; ID = intellectual disability; ILAE = International League Against Epilepsy; STXBP1 = syntaxin-binding protein 1; STXBP1-E = STXBP1 encephalopathy.

Syntaxin-binding protein 1 (STXBP1) (also known as MUNC18-1) is a protein of the SEC1 family of membrane trafficking proteins predominantly expressed in the brain, which plays an important role in synaptic vesicle docking and fusion. ${ }^{1,2}$ Through interaction with both vesicle-associated (synaptobrevin 2 or vesicle-associated membrane protein 2) and targetassociated (syntaxin-1 and synaptosomal-associated protein 25) soluble N-ethylmaleimidesensitive factor attachment protein receptors (SNARE) proteins, STXBP1 modulates the presynaptic vesicular fusion reaction., ${ }^{3,4}$ STXBP1 is encoded by the STXBP1 gene (NM_003165.3), consisting of 20 exons and located on chromosome 9q34.11. . $^{2,5}$

In 2008, Saitsu et al. ${ }^{6}$ described de novo STXBP1 mutations in 5 patients with Ohtahara syndrome. Subsequently, mutations in STXBP1, including missense, frameshift, splice site, and nonsense mutations, and intragenic and whole gene deletions have been described in different patient cohorts, broadening the phenotypic spectrum of STXBP1 mutations to West syndrome, unclassified early-onset epileptic encephalopathy, Dravet syndrome, nonsyndromic epilepsy and intellectual disability, and autism.,

* Members of the STXBP1 study group.

Authors' affiliations are listed at the end of the article.

Go to Neurology.org for full disclosures. Funding information and disclosures deemed relevant by the authors, if any, are provided at the end of the article. 
Hiltrud Muhle, MD*

Judith Phalin, MSc*

Keri Ramsey, BSN, CCRN*

Antonino Romeo, MD*

Jens Schallner, MD*

Ina Schanze, MD*

Marwan Shinawi, MD*

Kristel Sleegers, MD, $\mathrm{PhD}^{*}$

Katalin Sterbova, MD*

Steffen Syrbe, MD*

Monica Traverso, $\mathrm{PhD}$ *

Andreas Tzschach, MD*

Peter Uldall, MD, PhD*

Rudy Van Coster, MD, PhD*

Helene Verhelst, MD*

Maurizio Viri, MD*

Susan Winter, MD*

Markus Wolff, MD*

Martin Zenker, MD*

Leonardo Zoccante, MD*

Peter De Jonghe, MD,

$\mathrm{PhD}$

Ingo Helbig, MD

Pasquale Striano, MD, $\mathrm{PhD}$

Johannes R. Lemke, MD

Rikke S. Møller, MSc,

$\mathrm{PhD}$

Sarah Weckhuysen, MD, $\mathrm{PhD}$

Correspondence to

Dr. Weckhuysen:

sarah.weckhuysen@molgen.vib-ua.be

or Dr. Møller:

rimo@filadelfia.dk

Supplemental data at Neurology.org
In this study, we aimed to provide a comprehensive picture of the phenotypic spectrum of STXBP1 encephalopathy (STXBP1-E). We report 45 previously unreported patients with STXBP1-E, carrying 33 unreported mutations, and summarize all STXBP1 mutations reported to date. We further discuss future treatment options and pitfalls in the genetic diagnosis of STXBP1-E.

METHODS Characterization of novel patients with $S T X B P 1-E$. Forty-five previously unreported patients with a STXBP1 mutation were included in this study. All patients were referred through a network of collaborating clinicians and geneticists. Mutations in STXBP1 were identified in research or diagnostic laboratories. Referring physicians were provided a standardized phenotyping sheet to assess relevant clinical characteristics, EEG, and neuroimaging findings. International League Against Epilepsy (ILAE) criteria were used for epilepsy syndrome classification, meaning that the diagnosis of Ohtahara syndrome, Dravet syndrome, West syndrome, or Lennox-Gastaut syndrome was only made when all criteria for seizure, developmental, and EEG characteristics were present. For the purpose of this review, we classified patients with frequent seizures and intellectual disability (ID), both with onset in the first 2 years of life but not fulfilling ILAE criteria for any specific syndrome, as earlyonset epilepsy and encephalopathy (EOEE; see Discussion). In case of preexisting developmental delay or ID with epilepsy onset after age 2 years, a diagnosis of ID and nonsyndromic epilepsy was made.

Standard protocol approvals, registrations, and patient consents. Written informed consent for participation in the study was obtained. The study was approved by the Commission of Medical Ethics of the University of Antwerp and the Ethics Committee of Western Zealand, Denmark.

Review of patients reported in literature. We performed a PubMed search for STXBP1. Articles not available in English were excluded. We also included microdeletions involving multiple genes in addition to $S T X B P 1$ even though we recognize that in these patients, deletions of other genes than STXBP1 might influence the phenotype.

We classified all patients as explained above, based on clinical information in the publication. For patients for whom no or little clinical information was reported, we listed the phenotype mentioned in the respective publications, but they were not included in summary statistics.

Statistical analyses. A $\chi^{2}$ test was used to compare mutation type (missense vs truncating) and cognitive outcome (mild to moderate ID vs severe to profound) and cognitive outcome and seizure outcome (seizure-free vs not seizure-free). A Fisher exact test was used in case any of the cells had an expected count below 5 . A nonparametric Mann-Whitney $U$ test was used to look for a difference in age at seizure onset, age when seizure-free, and duration of seizures between the groups with truncating mutations and missense mutations and between the groups with mild to moderate ID and severe to profound ID. Statistical analyses were performed with SPSS Statistics 22 (IBM, Armonk, NY).

To estimate the frequency of STXBP1-E in the general population, we used the electronic population databases of National Statistics at the Statens Serum Institute (Denmark) to calculate the birth cohort from 2001 to 2010. The Danish Epilepsy Centre is the only tertiary hospital in Denmark specialized in the treatment of epilepsy, and the majority of patients with intractable epilepsy are referred to this center. To ensure that all Danish patients diagnosed with STXBP1-E were included, including patients with mild or no epilepsy, we contacted all major Danish pediatric departments and clinical genetics departments for STXBP1-E patients treated locally.

RESULTS STXBP1: The phenotypic spectrum. In total, we reviewed the phenotypic features of 147 patients with STXBP1-E, including 45 previously unreported patients described in this article (tables e-1, e-2, and e-3 on the Neurology ${ }^{\circledR}$ Web site at Neurology.org). Age at inclusion ranged from 6 months to 56 years (median 5 . 75 years). At onset, the majority of patients had a clinical diagnosis of EOEE $(\mathrm{n}=71 ; 53 \%)$ or Ohtahara syndrome $(n=28,20.9 \%), 27$ of whom showed evolution to West syndrome over time. STXBP1 mutations were also identified in patients initially presenting with West syndrome $(\mathrm{n}=13$; $9.7 \%$ ), ID with nonsyndromic epilepsy ( $\mathrm{n}=8$; $6 \%)$, ID without epilepsy $(\mathrm{n}=9 ; 6.7 \%)$, or Dravet syndrome $(n=3 ; 2.2 \%)$. One patient had early myoclonic encephalopathy and 1 patient had ID with 2 possible seizures. For 13 patients, no clinical description was available. Four of the 9 patients with ID without epilepsy were identified in the group of previously unreported patients.

Seizures in STXBP1-E. If present, epilepsy onset in STXBP1-E tends to be early in life, with a median onset age of 6 weeks (range 1 day-12 years). Childhood-onset epilepsy has been described in 8 patients with first seizures occurring at up to 12 years of age.

A broad spectrum of seizure types is seen in patients with STXBP1-E. Most frequently, epileptic spasms occur at some stage during the disease course (65.3\%). Other frequent seizure types are focal seizures $(57.9 \%)$ and tonic seizures (41.3\%).

Treatment of seizures is often difficult early in the disease. Fifty-six of 104 (53.8\%) patients for whom this information was available were treated with more than 3 antiepileptic drugs (AEDs) (steroid treatment and ACTH included). At last follow-up, 29 of 101 patients (28.7\%) for whom information was available still had frequent seizures (more than once a week) despite treatment. Forty-six patients out of 105 for whom information was available (43.8\%) nevertheless became seizurefree between the ages of 1 month and 4 years with a median age of 8 months. One patient became seizure-free after corpus callosotomy; in another patient, epilepsy surgery with resection of a focal cortical dysplasia greatly reduced seizure frequency. ${ }^{10,18}$

For the 40 newly diagnosed patients with epilepsy, different combinations of AEDs led to seizure 
freedom. Although numbers are small, the AEDs most frequently reported to be effective were valproic acid, which led to seizure freedom in 4 patients (patients 4, 9, 32, and 39), levetiracetam in 3 patients (patients 2, 36, and 43), and vigabatrin in 2 patients (patients 28 and 41). In 8 out of 14 patients who became seizure-free, treatment with AEDs eventually could be discontinued. It should be noted that epilepsy relapse after a longer period of seizure freedom has been reported in 6 older patients with STXBP1 mutations. ${ }^{5,12,16}$

EEG and MRI characteristics. In most patients with STXBP1-E, focal or multifocal epileptic activity on EEG was described (64.1\%). A burst-suppression pattern was present at some point in disease history in 42 patients $(35.9 \%)$ and hypsarrhythmia in 44 patients $(40 \%)$.

Following the recent description of MRI characteristics in patients with STXBP1-E by Barcia et al., ${ }^{25}$ we reviewed all patients for the presence of cerebral atrophy, thin corpus callosum, and an aberrant myelination pattern on brain MRI. Information on MRI was present in 117 patients. Atrophic changes were described in $39(33.3 \%)$ patients and thin corpus callosum or hypomyelination/delayed myelination in 19 patients each (16.2\%). In 55 patients $(47 \%)$, MRI was reported as normal.

Development, behavior, and neurologic features. All patients had some degree of ID, and in 107 out of 121 patients $(88.4 \%)$ for whom information was available severe to profound ID was reported. In only 1 patient with a de novo p.Asp285Tyr mutation, cognitive impairment was limited to learning difficulties. ${ }^{27}$ More detailed information regarding development was available for all 45 of our previously unreported patients: of the 28 patients with epilepsy onset after the neonatal period (after 30 days), 18 (64.3\%) had preexisting developmental delay (information of early development not available in 1 patient). Out of all 45 unreported patients, 4 showed developmental regression (patients 1, 16, 34, and 37). In one patient (patient $34)$, regression occurred prior to epilepsy onset. Twenty-one out of 45 patients obtained the ability to walk (some steps) independently, acquiring this skill between the ages of 14 months and 6 years. Two learned to walk and then lost this ability later. Seven patients were able to speak more than a few words, allowing for some degree of verbal communication.

Autism or autistic features have been reported in 25 of the 147 patients reviewed. Fourteen of these patients (31.1\% out of 45 patients) were identified in our cohort of previously unreported patients where this feature was specifically addressed in the questionnaire. Stereotypies have been described in 31 out of 147 patients. Other behavioral problems mentioned were hyperactivity $(n=6)$ and acting out or aggressive behavior $(\mathrm{n}=5)$.

Finally, a number of neurologic symptoms have been associated with STXBP1-E, including pyramidal, extrapyramidal, and cerebellar features suggesting involvement of various neurologic systems. The most frequent findings were (axial) hypotonia $(\mathrm{n}=39)$, ataxia or ataxic gait $(\mathrm{n}=34)$, (intentional) tremor $(\mathrm{n}=31)$, spasticity $(\mathrm{n}=20)$, dyskinesia $(\mathrm{n}=17)$, and dystonia $(\mathrm{n}=14)$. Following a recent report of a patient with STXBP1-E and juvenile-onset parkinsonism, we reviewed all new patients for features of parkinsonism. ${ }^{30}$ We identified 2 adult patients (both aged 20 years; $2 / 12$ patients older than 12 years) with prominent extrapyramidal features; 2 additional patients had only hypomimic facies.

Table 1 and figure 1 provide a summary of the phenotypic features associated with STXBP1-E.

Mutation spectrum and inheritance. Table e-2 provides an overview of all 147 STXBP1 mutations reported to date, accounting for 123 different mutations including 33 previously unreported mutations. Out of 147 mutations, 56 (38.1\%) were missense mutations (figure 2), and $91(61.9 \%)$ were truncating mutations including nonsense $(n=21)$, splice site $(n=24)$, and frameshift mutations $(\mathrm{n}=19)$, partial and whole gene deletions, and larger microdeletions including STXBP1 ( $\mathrm{n}=25)$ (figure e-1). One patient (patient 28 of the new cohort) had a de novo synonymous mutation in an essential splice site, predicted to lead to a loss of the donor splice site (Human Splice Finder), and one patient had a small in-frame deletion. None of the mutations was present in the ExAC database (http://exac.broadinstitute.org/). Forty-one missense mutations were predicted deleterious or possibly/ probably damaging by both SIFT and PolyPhen-2, 14 only by SIFT, and 1 was predicted benign by both tools (de novo p.His445Pro mutation in a patient with Dravet syndrome). Out of all mutations, 124 (84.4\%) mutations were demonstrated to be de novo. One STXBP1 mutation was inherited from a father carrying a mosaic mutation. ${ }^{9}$ Two mutations were absent in the mother and for 20 mutations information on inheritance was not available, including 6 mutations of previously unreported patients. Five of these 6 mutations were truncating and thus considered to be pathogenic. The sixth mutation (patient 25) was a recurrent missense mutation, absent in the mother, and proven to occur de novo in 2 other unrelated patients.

In total, 13 recurrent mutations have been reported, including the missense mutations p.Arg406His in 7 patients and p.Arg551Cys in 4 patients. Seven recurrent mutations occurred at $\mathrm{CpG}$ dinucleotides leading to the substitution of an arginine residue. 


\section{Table 1 Clinical features of STXBP1 encephalopathy}

Epilepsy

Approximately $95 \%$ of patients

Most frequent seizure types are epileptic spasms (65.3\%), focal seizures $(57.9 \%)$, and tonic seizures $(41.3 \%)$

Seizure freedom is achieved in more than 1 in 3 patients, almost 1 in 3 remain therapyresistant

EEG

$>60 \%$ have focal or multifocal epileptic activity

Burst suppression (35.9\%) and hypsarrhythmia (40\%) are frequent EEG findings

Intellectual disability

All patients; the majority has severe to profound intellectual disability (88.4\%)

Behavioral problems

Autism or autistic features are seen in almost 1 in 5 patients

Motor features

(Axial) hypotonia, ataxia or ataxic gait, (intentional) tremor, spasticity and dyskinesia, or dystonia are frequently seen

Imaging (brain MRI)

Normal in almost $1 / 2$

Cerebral atrophy (33.3\%), thin corpus callosum (16.2\%), and hypomyelination or delayed myelination $(16.2 \%)$ are frequent (age related) findings

There was no obvious clustering of mutations in any of the 3 STXBP1 domains (figure 2, figure e-1).

Genotype-phenotype correlations. We examined whether truncating mutations are associated with a more severe phenotype than missense mutations, and whether recurrent mutations lead to similar phenotypes. Forty-one of 45 patients with missense mutations for whom information on cognition was available had severe to profound ID (91.1\%), compared to 66 out of 76 in patients with truncating mutations $(86.8 \%)$. Out of the 9 patients without epilepsy, 3 carried missense mutations and 6 carried truncating mutations. In the group of 31 patients

\section{Figure 1 Spectrum of STXBP1-associated phenotypes}

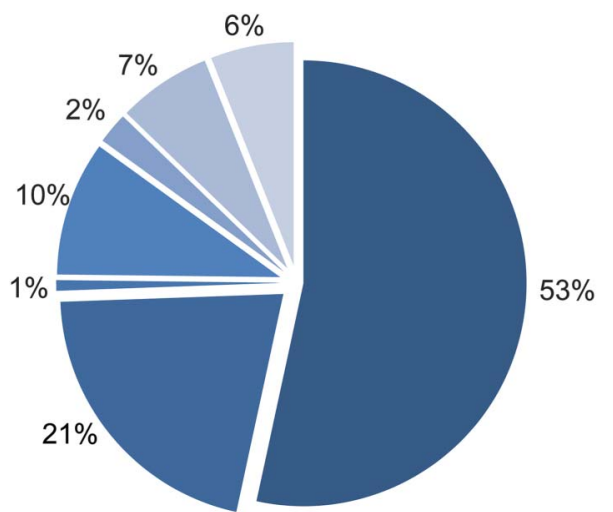

- EOEE

$\because \mathrm{OS}$

aME

West

Dravet

ID, no epilepsy

NSE + ID
Epilepsy syndrome classification made as of age at onset of seizures. EME = early myoclonic encephalopathy; EOEE = early-onset epilepsy and encephalopathy; ID = intellectual disability; NSE + ID = nonsyndromic epilepsy and intellectual disability; OS = Ohtahara syndrome. who became seizure-free within 1 year after seizure onset, 9 carried missense mutations and 22 truncating mutations. These data suggest that truncating mutations do not necessarily lead to a more severe phenotype. The 7 patients with the most frequent recurrent mutation p.Arg406His all had onset of epilepsy in the first 2.5 months of life with severe to profound ID while the seizure phenotype and cognitive outcome was more variable for the other recurrent mutations including p.Arg292Cys, p.Arg292His, and p.Arg551Cys.

We next performed a statistical analysis of phenotype-genotype relationships (e-Methods and e-Results). No significant correlation was found between mutation type (missense vs truncating) and cognitive outcome (learning difficulties, mild to moderate ID, vs severe to profound ID; $\chi^{2}, 2$-sided $p=$ 0.478 ) or between mutation type and seizure outcome (seizure-free vs not seizure-free; $\chi^{2}, 2$-sided $p=0.127$ ). There was also no significant difference between the different mutation types regarding age at seizure onset (Mann-Whitney $U$, 2-tailed $p=0.333$ ) or age at seizure freedom (Mann-Whitney $U$, 2-tailed $p=0.225$, figure e-2). Furthermore, there was no significant correlation between seizure outcome and cognitive outcome (Fisher exact, 2-sided $p=0.486$ ), and no statistical difference between the groups with learning difficulties, mild or moderate ID, and severe to profound ID with regard to age at seizure onset (MannWhitney $U, 2$-tailed $p=0.393$ ), age at seizure freedom (Mann-Whitney $U$, 2-tailed $p=0.603$, figure e-3), and duration of seizures (time between seizure onset and seizure freedom or age at inclusion; Mann-Whitney $U, 2$-tailed $p=0.809$ ).

Frequency of $S T X B P 1-E$. Seven Danish children born between 2001 and 2010 were referred to the Danish Epilepsy Centre and diagnosed with STXBP1-E. None was treated outside the Epilepsy Centre. According to the 10-year Danish birth cohort from 2001 to 2010, the number of live births in Denmark in this period was 643,039. Based on these numbers, we estimated that the frequency of STXBP1-E in the Danish population is at least 1 : 91,862 .

DISCUSSION STXBP1 plays an important role in vesicular docking and fusion, a necessary mechanism for neurotransmitter secretion. An STXBP1 knockout mouse model showed that total disruption of STXBP1 leads to a complete loss of neurotransmitter secretion from synaptic vesicles. STXBP1 knockout mice further showed neurodegeneration after an initially normal brain assembly, indicating that neurotransmitter secretion, and thus functional STXBP1, is important for the maintenance of neuronal synapses. ${ }^{42}$ Reduced STXBP1 expression was further shown to 


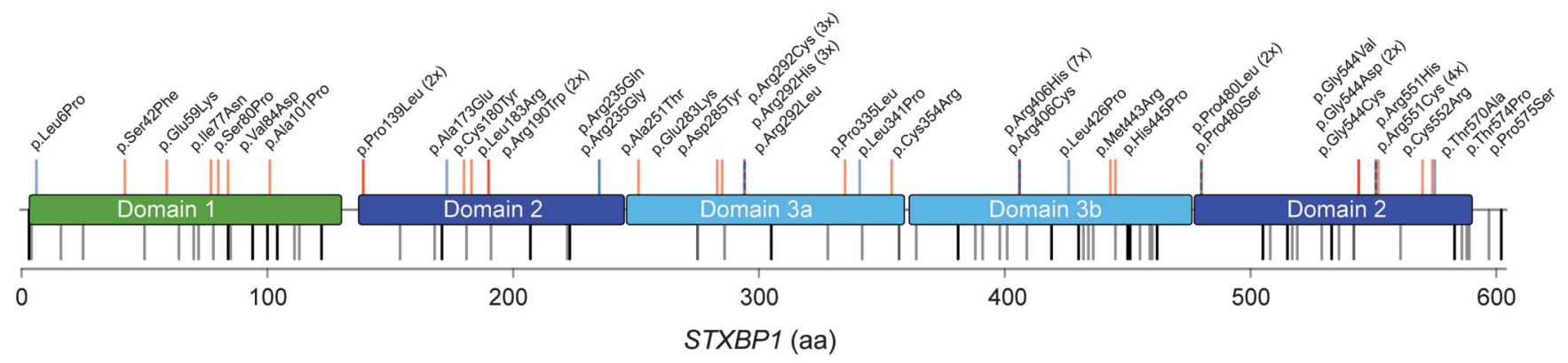

STXBP1 missense mutations located on the protein that consists of 3 domains. There is no obvious clustering in either of the domains. The blue bars represent the previously unreported mutations, the red bars the already published mutations, and the red and blue bars the mutations seen in newly diagnosed and previously reported patients. The gray bars represent the ExAC missense variants reported once, the black the missense variants reported more than once. None of the mutations reported in patients with STXBP1 encephalopathy is seen in ExAC.

increase synaptic depression at both GABAergic and glutamatergic synapses with a greater impact on GABAergic interneurons. ${ }^{43}$ This might result in a net hyperexcitability and epileptic activity in case of STXBP1 haploinsufficiency.

Over recent years, the phenotypic spectrum of patients with STXBP1 mutations has expanded. One goal of our study was to assess the phenotypic spectrum of STXBP1-E. We found that ID and epilepsy present the 2 major, independent, phenotypic dimensions of STXBP1-E. All patients with STXBP1-E have some degree of ID, which is severe to profound in almost $90 \%$ of patients. Ninety-five percent of patients have epilepsy, although a recruitment bias towards patients with epilepsy might be present in many articles that were reviewed for our study.

Although stagnation of development can be seen at seizure onset, some degree of developmental delay is already present prior to seizure onset in many patients. Regression is rarely seen, and does not always seem to be related to seizure activity. We did not find a relationship between the age at onset or duration of seizures and the degree of intellectual impairment, although the power of our analyses was limited. This reinforces the notion that STXBP1 plays an important role in many aspects of neurodevelopment and that STXBP1-E is not a pure epileptic encephalopathy. A similar, but less evident, observation has been made in other severe genetic epilepsies such as Dravet syndrome. ${ }^{44}$ For the purpose of this article, we therefore chose to define EOEE as early-onset epilepsy and encephalopathy, rather than early-onset epileptic encephalopathy.

With regards to the epilepsy phenotype, about one-third of patients present with either Ohtahara or West syndrome. Approximately one-quarter of patients with EOEE or Ohtahara syndrome evolve to West syndrome over time. While most patients do not fulfill precise ILAE criteria for these particular electroclinical syndromes, the majority of the patients with epilepsy have epileptic spasms or tonic seizures at some point in their disease history. Accordingly, this constellation may be considered the core seizure phenotype of STXBP1-E. More than one-third of the patients eventually become seizure-free; however, in some patients, epilepsy remains difficult to control.

The main EEG finding is (multi)focal epileptic activity, while burst-suppression or hypsarrhythmia are seen in approximately one-third of patients. MRI of the brain is normal in almost half of the patients. Nevertheless, cortical atrophy, delayed myelination, and thin corpus callosum are recurrent findings. Since MRI features are partially age-dependent, aberrant MRI findings might be underreported because of the young age of some of the patients reported.

Most patients with STXBP1-E present with additional neurologic features after infancy besides ID and epilepsy. Autism or autistic features are present in almost $20 \%$ of published cases, but might also be underreported due to the focus of most studies on the epilepsy phenotype. The combination of stereotypies, autistic features, and regression in some patients explains the identification of STXBP1 mutations in a few patients with atypical Rett syndrome. ${ }^{37,38}$ Furthermore, patients with STXBP1-E frequently have additional neurologic features, including dyskinesia, dystonia, tremor, (axial) hypotonia, and ataxia, which suggest an impairment of various neurologic systems. Moreover, in our cohort of previously unreported patients, we identified 2 patients with extrapyramidal features at age 20 years. Levodopa-responsive parkinsonism has been described in adult patients with Dravet syndrome. ${ }^{45}$ Further studies in adult patients with STXBP1-E are warranted to establish the prevalence of parkinsonism at older age, and to study the effect of treatment with levodopa.

Treatment of STXBP1-E warrants a multidisciplinary approach, and currently consists of symptomatic treatment of seizures and behavioral and locomotor 
problems with physical therapy and occupational therapy to maximize the developmental potential. A good response of epileptic spasms to vigabatrin has been reported in several studies, ${ }^{7,12,13,19,24,25,37}$ as has a good effect of valproic acid ${ }^{12,25}$ and levetiracetam. ${ }^{40,46}$ The latter is an interesting observation given that levetiracetam acts through modulation of synaptic vesicle release. ${ }^{40,47}$ However, these beneficial effects are only seen in some selected patients and larger prospective studies are needed to identify the most favorable antiepileptic treatment regimen for STXBP1-E. Improvement of prognosis on both seizure and cognitive outcome may further come from the development of a targeted disease-modifying treatment. For example, protein-protein interaction inhibition has been suggested as a possible therapeutic strategy in STXBP1 haploinsufficiency. ${ }^{48}$ Finally, STXBP1 was recently shown to play a role in endothelial granule exocytosis, and a significantly impaired histamine and stimulated von Willebrand Factor secretion was observed in a patient with STXBP1-E. ${ }^{49}$ Although this was insufficient to result in clinical symptoms, this decrease might be a good biomarker to monitor the effect of future targeted therapies.

Both de novo missense mutations and truncating mutations or deletions can lead to STXBP1-E. In our analyses, we did not find any correlation between mutation type and the presence of seizures, age at seizure onset, or cognitive outcome. Also taking into account the phenotypic variability seen in patients with some of the recurrent de novo mutations, other factors such as genetic background or environmental factors may play a role in defining the eventual phenotype.

Confirming a pathogenic mutation and making a diagnosis of STXBP1-E is not always straightforward. Truncating mutations in STXBP1 are generally considered to be pathogenic. However, different truncating variants have been described in the ExAC database. All are located at the end of the last exon, outside the last domain 2, while all causative STXBP1 truncating mutations are positioned prior to this region (figure e-1). Possibly, the truncating ExAC variants escape nonsense-mediated decay and may lead to a functional protein. Moreover, it remains unclear whether the 6 individuals carrying any of the 4 truncating variants are healthy controls or derived from cohorts with late-onset neuropsychiatric disorders who were recruited for ExAC.

Missense variants can be found in both healthy individuals and patients with STXBP1-E. Four of the 21 STXBP1 missense variants occurring more than once in the ExAC database are predicted deleterious by both SIFT and PolyPhen-2 (figure 2), demonstrating the limitations of in silico prediction tools alone for clinical interpretation of missense variants. On the other hand, one missense mutation, p.His445Pro, identified in a patient with Dravet syndrome, was predicted benign by both SIFT and PolyPhen-2. ${ }^{27}$ This variant was classified as pathogenic based on its de novo status. Therefore, interpretation of novel STXBP1 missense variants will remain challenging in the absence of segregation data.

In this study, we describe 45 previously unreported patients with STXBP1-E, resulting in a total of 147 reported patients. These numbers suggest that $S T X B P 1$ mutations are among the most frequent causative mutations in patients with epilepsy and ID next to genes like SCN1A, CDKL5, MECP2, and KCNQ2. We estimate a frequency of 1:91,862 in a Danish birth cohort, but this number might be an underestimate since STXBP1-E is a heterogeneous condition and some patients may be undiagnosed. We illustrate the phenotypic spectrum of STXBP1-E and hypothesize that STXBP1-E should be considered a complex neurodevelopmental disorder rather than a primary epileptic encephalopathy.

\section{AUTHOR AFFILIATIONS}

Neurogenetics Group (H.S., P.D.J., S. Weckhuysen) and the Neurodegenerative Brain Diseases Group (K. Sleegers), Department of Molecular Genetics, VIB, Antwerp; Laboratory of Neurogenetics, Institute BornBunge (H.S., K. Sleegers, P.D.J., S. Weckhuysen), and Department of Neurology, Antwerp University Hospital (H.S., P.D.J.), University of Antwerp, Belgium; Danish Epilepsy Centre (M.N., P.U., R.S.M.), Dianalund, Denmark; Departments of Human Genetics (M.H.W.) and Pediatric Neurology (C.E.E.), Radboud University Medical Center, Nijmegen, the Netherlands; Division of Child Neurology (P.A., L.G.), Spedali Civili di Brescia, Italy; Child Neurology and Neurorehabilitation Unit (M.A., G. Casara), Department of Pediatrics, Central Hospital of Bolzano, Italy; Department for Epileptology (H.B., N.M.), Sinova Kliniken ZfP Südwürttemberg, Ravensburg; Klinik für Kinderneurologie und Kinderneurologisches Zentrum (I.B.-H.), Sana Kliniken Düsseldorf, Germany; Centre de Génétique Humaine (V.B., M.D., A.D., D.L.), Institut de Pathologie et Génétique, Charleroi (Gosselies), Belgium; Unità Specialistica di Neurologia Pediatrica (M.B.), Presidio Ospedaliero di Cava de' Tirreni, Salerno, Italy; Institute of Human Genetics (A.C.), Christian-Albrechts-University Kiel \& University Hospital SchleswigHolstein, Campus Kiel, Germany; Child Neuropsychiatry Unit (G. Cantalupo, L.Z.), Department of Life and Reproduction Sciences, University of Verona; Neuropsichiatria Infantile (G. Capovilla), Dipartimento Materno-Infantile, Azienda Ospedaliera Carlo Poma, Manotva, Italy; Division of Human Genetics (C.C.), Department of Pediatrics, Inselspital, University of Bern, Switzerland; Servizio di Epilettologia e Neurofisiopatologia Pediatrica, Neurofisiopatologia (R.D.), Fondazione IRCCS Ca' Granda Ospedale Maggiore Policlinico, Milan, Italy; Department of Medical Genetics (M.F., R.F.), Oslo University Hospital; University of Oslo (R.F.), Norway; Division of Clinical Genomics (K.L.H.), Ambry Genetics, Aliso Viejo, CA; Institute of Human Genetics (H.O.H., J.R.L.) and Department of Women and Child Health, Hospital for Children and Adolescents (A.M., S.S.), University of Leipzig, Germany; Children's Hospital Aschaffenburg (J.K.), Am Hasenkopf, Aschaffenburg, Germany; Neuropediatric Clinic and Clinic for Neurorehabilitation (G.J.K.), Epilepsy Center for Children and Adolescents, Schön Klinik Vogtareuth, Germany; PMU Salzburg (G.J.K.), Austria; Pediatric Neurology Unit and Epilepsy Center "Fatebenefratelli e Oftalmico" Hospital (M.L., A.R., M.V.), Milan, Italy; Department of Child Neurology, Development and Rehabilitation (KER-Zentrum) (O.M.), Children's Hospital of Eastern Switzerland, St. Gallen, Switzerland; Pediatric Neurology and Muscular Diseases Unit, Department of Neurosciences, Rehabilitation, Ophthalmology, Genetics, Maternal and Child Health, University of 
Genoa (C.M., P.S.), and Laboratory of Neurogenetics, Department of Neurosciences (M.T.), “G. Gaslini” Institute, Genova, Italy; Department of Neuropediatrics (H.M., I.H.), Christian-Albrechts-University Kiel \& University Hospital Schleswig-Holstein, Campus Kiel, Germany; Department of Medical Genetics and Metabolism (J.P., S. Winter), Valley Children's Hospital, Madera, CA; Center for Rare Childhood Disorders (K.R.), Translational Genomics Research Institute, Phoenix, AZ; Department of Neuropediatrics (J.S.), University Clinic Carl Gustav Carus, Dresden, Germany; Institute of Human Genetics (I.S., M.Z.), University Hospital, Magdeburg, Germany; Department of Pediatrics (M.S.), Division of Genetics and Genomic Medicine, Washington University School of Medicine, St. Louis, MO; Department of Child Neurology (K. Sterbova), 2nd Faculty of Medicine, Charles University, Motol Hospital, Prague, Czech Republic; Institute of Clinical Genetics (A.T.), Technische Universität Dresden, Germany; Institute of Medical Genetics and Applied Genomics (A.T.) and Department of Neuropediatrics (M.W.), University of Tübingen, Germany; Child and Adolescence Department (P.U.), Rigshospitalet, University of Copenhagen, Denmark; Department of Pediatrics (R.V.C., H.V.), Division of Pediatric Neurology and Metabolism, Ghent University Hospital, Belgium; Division of Neurology (I.H.), Children's Hospital of Philadelphia, PA; Institute for Regional Health Services (R.S.M.), University of Southern Denmark, Odense, Denmark; INSERM U 1127 (S. Weckhuysen), UMR 7225, Centre National de la Recherche Scientifique, Université Pierre et Marie Curie; and UMR S 1127, Institut du Cerveau et de la Moelle Épinière (S. Weckhuysen), Sorbonne Universités, Paris, France.

\section{AUTHOR CONTRIBUTIONS}

Hannah Stamberger: drafting/revising the manuscript, analysis or interpretation of data, accepts responsibility for conduct of research and final approval, statistical analysis. Marina Nikanorova: drafting/revising the manuscript, accepts responsibility for conduct of research and final approval, contribution of vital reagents/tools/patients. Marjolein H. Willemsen: drafting/revising the manuscript, accepts responsibility for conduct of research and final approval, collection and clinical description of patients. Patrizia Accorsi: drafting/revising the manuscript, accepts responsibility for conduct of research and final approval, acquisition of data study supervision. Marco Angriman: drafting/revising the manuscript, accepts responsibility for conduct of research and final approval. Hartmut Baier: drafting/revising the manuscript, accepts responsibility for conduct of research and final approval, acquisition of data. Ira Benkel-Herrenbrueck: analysis or interpretation of data, accepts responsibility for conduct of research and final approval, acquisition of data. Valérie Benoit: analysis or interpretation of data, accepts responsibility for conduct of research and final approval. Mauro Budetta: analysis or interpretation of data, accepts responsibility for conduct of research and final approval, acquisition of data. Almuth Caliebe: analysis or interpretation of data, accepts responsibility for conduct of research and final approval, acquisition of data. Gaetano Cantalupo: analysis or interpretation of data, accepts responsibility for conduct of research and final approval, acquisition of data, phenotype description. Giuseppe Capovilla: analysis or interpretation of data, accepts responsibility for conduct of research and final approval, acquisition of data. Gianluca Casara: drafting/revising the manuscript, accepts responsibility for conduct of research and final approval. Carolina Courage: drafting/revising the manuscript, accepts responsibility for conduct of research and final approval, acquisition of data. Marie Deprez: drafting/revising the manuscript, accepts responsibility for conduct of research and final approval. Anne Destrée: drafting/revising the manuscript, accepts responsibility for conduct of research and final approval, acquisition of data. Robertino Dilena: drafting/revising the manuscript, accepts responsibility for conduct of research and final approval, acquisition of data. Corrie E. Erasmus: drafting/revising the manuscript, accepts responsibility for conduct of research and final approval, acquisition of data. Madeleine Fannemel: drafting/revising the manuscript, accepts responsibility for conduct of research and final approval, acquisition of data. Roar Fjær: drafting/revising the manuscript, accepts responsibility for conduct of research and final approval, acquisition of data. Lucio Giordano: drafting/revising the manuscript, accepts responsibility for conduct of research and final approval, study supervision. Katherine L. Helbig: drafting/revising the manuscript, accepts responsibility for conduct of research and final approval, acquisition of data. Henrike O. Heyne: analysis or interpretation of data, accepts responsibility for conduct of research and final approval. Joerg Klepper: drafting/revising the manuscript, accepts responsibility for conduct of research and final approval, acquisition of data. Gerhard J. Kluger: drafting/revising the manuscript study concept or design, analysis or interpretation of data, accepts responsibility for conduct of research and final approval, acquisition of data. Damien Lederer: drafting/revising the manuscript, analysis or interpretation of data, accepts responsibility for conduct of research and final approval, acquisition of data. Monica Lodi: analysis or interpretation of data, accepts responsibility for conduct of research and final approval, acquisition of data. Oliver Maier: drafting/ revising the manuscript, accepts responsibility for conduct of research and final approval, contribution of vital reagents/tools/patients. Andreas Merkenschlager: drafting/revising the manuscript, analysis or interpretation of data, accepts responsibility for conduct of research and final approval, acquisition of data. Nina Michelberger: drafting/revising the manuscript, accepts responsibility for conduct of research and final approval, acquisition of data. Carlo Minetti: drafting/revising the manuscript, analysis or interpretation of data, accepts responsibility for conduct of research and final approval, study supervision. Hiltrud Muhle: analysis or interpretation of data, accepts responsibility for conduct of research and final approval, acquisition of data, contribution of patients. Judith Phalin: drafting/revising the manuscript, accepts responsibility for conduct of research and final approval, acquisition of data. Keri Ramsey: drafting/ revising the manuscript, accepts responsibility for conduct of research and final approval, acquisition of data. Antonino Romeo: analysis or interpretation of data, accepts responsibility for conduct of research and final approval, acquisition of data. Jens Schallner: drafting/revising the manuscript, accepts responsibility for conduct of research and final approval. Ina Schanze: analysis or interpretation of data, accepts responsibility for conduct of research and final approval, contribution of vital reagents/ tools/patients. Marwan Shinawi: drafting/revising the manuscript, accepts responsibility for conduct of research and final approval, acquisition of data. Kristel Sleegers: drafting/revising the manuscript analysis or interpretation of data, accepts responsibility for conduct of research and final approval, statistical analysis. Katalin Sterbova: analysis or interpretation of data, accepts responsibility for conduct of research and final approval, acquisition of data. Steffen Syrbe: analysis or interpretation of data, accepts responsibility for conduct of research and final approval, acquisition of data. Monica Traverso: analysis or interpretation of data, accepts responsibility for conduct of research and final approval, acquisition of data. Andreas Tzschach: drafting/revising the manuscript accepts responsibility for conduct of research and final approval, acquisition of data. Peter Uldall: drafting/revising the manuscript, accepts responsibility for conduct of research and final approval, acquisition of data. Rudy Van Coster: analysis or interpretation of data, accepts responsibility for conduct of research and final approval, acquisition of data. Helene Verhelst: drafting/revising the manuscript, analysis or interpretation of data, accepts responsibility for conduct of research and final approval, acquisition of data. Maurizio Viri: drafting/revising the manuscript, accepts responsibility for conduct of research and final approval, acquisition of data. Susan Winter: drafting/revising the manuscript, accepts responsibility for conduct of research and final approval. Markus Wolff: drafting/revising the manuscript, accepts responsibility for conduct of research and final approval, acquisition of data. Martin Zenker: analysis or interpretation of data, accepts responsibility for conduct of research and final approval, acquisition of data. Leonardo Zoccante: analysis or interpretation of data, accepts responsibility for conduct of research and final approval, acquisition of data. Peter De Jonghe: drafting/revising the manuscript, study concept or design, analysis or interpretation of data, accepts responsibility for conduct of research and final approval, study supervision, obtaining funding. Ingo Helbig: drafting/revising the manuscript, analysis or interpretation of data, accepts responsibility for conduct of research and final approval, acquisition of data. Pasquale Striano: drafting/revising the manuscript, study concept or design, analysis or interpretation of data, accepts responsibility for conduct of research and final approval, acquisition of data, study supervision. Johannes R. Lemke: analysis or interpretation of data, accepts responsibility for conduct of research and final approval, acquisition of data. Rikke S. Møller: drafting/ revising the manuscript, study concept or design, analysis or 
interpretation of data, accepts responsibility for conduct of research and final approval, study supervision. Sarah Weckhuysen: drafting/ revising the manuscript, study concept or design analysis or interpretation of data, accepts responsibility for conduct of research and final approval, acquisition of data, study supervision.

\section{ACKNOWLEDGMENT}

The authors thank the patients and their families; all referring physicians and geneticists for providing detailed genetic and clinical data of their patients; Caroline van Cauwenberghe for advice regarding the statistics; and their neurogenetics group colleagues for advice.

\section{STUDY FUNDING}

Supported by the Eurocores program EuroEPINOMICS, the Fund for Scientific Research Flanders (FWO), the International Coordination Action (ICA) grant G0E8614N, and the University of Antwerp (research fund). H.S. is PhD fellow of the Fund for Scientific Research Flanders $(1125416 \mathrm{~N})$

\section{DISCLOSURE}

H. Stamberger, M. Nikanorova, M. Willemsen, P. Accorsi, M. Angriman, H. Baier, I. Benkel-Herrenbrueck, V. Benoit, M. Budetta, A. Caliebe, G. Cantalupo, C. Courage, M. Deprez, A. Destrée, R. Dilena, C. Erasmus, M. Fannemel, R. Fjær, and L. Giordano report no disclosures relevant to the manuscript. K. Helbig is employed by and receives a salary from Ambry Genetics. Exome sequencing is among its commercially available tests. H. Heyne, J. Klepper, G. Kluger, D. Lederer, M. Lodi, O. Maier, A. Merkenschlager, N. Michelberger, C. Minetti, H. Muhle, J. Phalin, K. Ramsey, A. Romeo, J. Schallner, I. Schanze, M. Shinawi, K. Sleegers, K. Sterbova, S. Syrbe, M. Traverso, A. Tzschach, P. Uldall, R. Van Coster, H. Verhelst, M. Viri, S. Winter, M. Wolff, M. Zenker, L. Zoccante, P. De Jonghe, I. Helbig, P. Striano, J. Lemke, R. Møller, and S. Weckhuysen report no disclosures relevant to the manuscript. Go to Neurology.org for full disclosures.

Received July 21, 2015. Accepted in final form November 16, 2015.

\section{REFERENCES}

1. Pevsner J, Hsu SC, Scheller RH. n-Sec1: a neural-specific syntaxin-binding protein. Proc Natl Acad Sci USA 1994; 91:1445-1449.

2. Swanson DA, Steel JM, Valle D. Identification and characterization of the human ortholog of rat STXBP1, a protein implicated in vesicle trafficking and neurotransmitter release. Genomics 1998;48:373-376.

3. Gerber SH, Rah JC, Min SW, et al. Conformational switch of syntaxin-1 controls synaptic vesicle fusion. Science 2008;321:1507-1510.

4. Shen J, Tareste DC, Paumet F, Rothman JE, Melia TJ. Selective activation of cognate SNAREpins by Sec1/Munc18 proteins. Cell 2007;128:183-195.

5. Hamdan FF, Piton A, Gauthier J, et al. De novo STXBP1 mutations in mental retardation and nonsyndromic epilepsy. Ann Neurol 2009;65:748-753.

6. Saitsu H, Kato M, Mizuguchi T, et al. De novo mutations in the gene encoding STXBP1 (MUNC18-1) cause early infantile epileptic encephalopathy. Nat Genet 2008;40: $782-788$.

7. Deprez L, Weckhuysen S, Holmgren P, et al. Clinical spectrum of early-onset epileptic encephalopathies associated with STXBP1 mutations. Neurology 2010;75: 1159-1165.

8. Saitsu H, Kato M, Okada I, et al. STXBP1 mutations in early infantile epileptic encephalopathy with suppressionburst pattern. Epilepsia 2010;51:2397-2405.

9. Saitsu H, Hoshino H, Kato M, et al. Paternal mosaicism of an STXBP1 mutation in OS. Clin Genet 2011;80:484-488.
10. Otsuka M, Oguni H, Liang JS, et al. STXBP1 mutations cause not only Ohtahara syndrome but also West syndrome: result of Japanese cohort study. Epilepsia 2010; 51:2449-2452.

11. Hamdan FF, Gauthier J, Dobrzeniecka S, et al. Intellectual disability without epilepsy associated with STXBP1 disruption. Eur J Hum Genet 2011;19:607-609.

12. Mignot C, Moutard ML, Trouillard O, et al. STXBP1-related encephalopathy presenting as infantile spasms and generalized tremor in three patients. Epilepsia 2011;52:1820-1827.

13. Milh M, Villeneuve N, Chouchane M, et al. Epileptic and nonepileptic features in patients with early onset epileptic encephalopathy and STXBP1 mutations. Epilepsia 2011; 52:1828-1834.

14. Saitsu H, Kato M, Shimono M, et al. Association of genomic deletions in the STXBP1 gene with Ohtahara syndrome. Clin Genet 2012;81:399-402.

15. Vatta M, Tennison MB, Aylsworth AS, et al. A novel STXBP1 mutation causes focal seizures with neonatal onset. J Child Neurol 2012;27:811-814.

16. Campbell IM, Yatsenko SA, Hixson P, et al. Novel 9q34.11 gene deletions encompassing combinations of four Mendelian disease genes: STXBP1, SPTAN1, ENG, and TOR1A. Genet Med 2012;14:868-876.

17. Rauch A, Wieczorek D, Graf E, et al. Range of genetic mutations associated with severe non-syndromic sporadic intellectual disability: an exome sequencing study. Lancet 2012;380:1674-1682.

18. Weckhuysen S, Holmgren P, Hendrickx R, et al. Reduction of seizure frequency after epilepsy surgery in a patient with STXBP1 encephalopathy and clinical description of six novel mutation carriers. Epilepsia 2013;54:e74-e80.

19. Mastrangelo M, Peron A, Spaccini L, et al. Neonatal suppression-burst without epileptic seizures: expanding the electroclinical phenotype of STXBP1-related, earlyonset encephalopathy. Epileptic Disord 2013;15:55-61.

20. Sampaio M, Rocha R, Biskup S, Leao M. Novel STXBP1 mutations in 2 patients with early infantile epileptic encephalopathy. J Child Neurol 2013;30:622-624.

21. Kim YO, Korff CM, Villaluz MM, et al. Head stereotypies in STXBP1 encephalopathy. Dev Med Child Neurol 2013;55:769-772.

22. Epi4K Consortium, Epilepsy Phenome/Genome Project, Allen AS, Berkovic SF, et al. De novo mutations in epileptic encephalopathies. Nature 2013;501:217-221.

23. Barcia G, Barnerias C, Rio M, et al. A novel mutation in STXBP1 causing epileptic encephalopathy (late onset infantile spasms) with partial respiratory chain complex IV deficiency. Eur J Med Genet 2013;56:683-685.

24. Romaniello R, Zucca C, Tenderini E, et al. A novel mutation in STXBP1 gene in a child with epileptic encephalopathy and an atypical electroclinical pattern. J Child Neurol 2014;29:249-253.

25. Barcia G, Chemaly N, Gobin S, et al. Early epileptic encephalopathies associated with STXBP1 mutations: could we better delineate the phenotype? Eur J Med Genet 2014;57:15-20.

26. Tucker $T$, Zahir FR, Griffith $M$, et al. Single exonresolution targeted chromosomal microarray analysis of known and candidate intellectual disability genes. Eur J Hum Genet 2014;22:792-800.

27. Carvill GL, Weckhuysen S, McMahon JM, et al. GABRA1 and STXBP1: novel genetic causes of Dravet syndrome. Neurology 2014;82:1245-1253. 
28. Michaud JL, Lachance M, Hamdan FF, et al. The genetic landscape of infantile spasms. Hum Mol Genet 2014;23: 4846-4858.

29. Matsumoto $\mathrm{H}$, Zaha $\mathrm{K}$, Nakamura $\mathrm{Y}$, Hayashi $\mathrm{S}$, Inazawa J, Nonoyama S. Chromosome 9q33q34 microdeletion with early infantile epileptic encephalopathy, severe dystonia, abnormal eye movements, and nephroureteral malformations. Pediatr Neurol 2014;51:170-175.

30. Keogh MJ, Daud D, Pyle A, et al. A novel de novo STXBP1 mutation is associated with mitochondrial complex I deficiency and late-onset juvenile-onset parkinsonism. Neurogenetics 2015;16:65-67.

31. Boutry-Kryza N, Labalme A, Ville D, et al. Molecular characterization of a cohort of 73 patients with infantile spasms syndrome. Eur J Med Genet 2015;58:51-58.

32. Neale BM, Kou Y, Liu L, et al. Patterns and rates of exonic de novo mutations in autism spectrum disorders. Nature 2012;485:242-245.

33. Nicita F, Ulgiati F, Bernardini L, et al. Early myoclonic encephalopathy in 9q33-q34 deletion encompassing STXBP1 and SPTAN1. Ann Hum Genet 2015;79: 209-217.

34. Mercimek-Mahmutoglu S, Patel J, Cordeiro D, et al. Diagnostic yield of genetic testing in epileptic encephalopathy in childhood. Epilepsia 2015;56:707-716.

35. Kodera H, Kato M, Nord AS, et al. Targeted capture and sequencing for detection of mutations causing early onset epileptic encephalopathy. Epilepsia 2013; 54:1262-1269.

36. Carvill GL, Heavin SB, Yendle SC, et al. Targeted resequencing in epileptic encephalopathies identifies de novo mutations in CHD2 and SYNGAP1. Nat Genet 2013;45: 825-830.

37. Romaniello R, Saettini F, Panzeri E, Arrigoni F, Bassi MT, Borgatti R. A de-novo STXBP1 gene mutation in a patient showing the Rett syndrome phenotype. Neuroreport 2015;26:254-257.

38. Olson HE, Tambunan D, LaCoursiere C, et al. Mutations in epilepsy and intellectual disability genes in patients with features of Rett syndrome. Am J Med Genet A 2015; 167A:2017-2025.

39. Tso WW, Kwong AK, Fung CW, Wong VC. Folinic acid responsive epilepsy in Ohtahara syndrome caused by STXBP1 mutation. Pediatr Neurol 2014;50:177-180.

40. Dilena R, Striano P, Traverso M, et al. Dramatic effect of levetiracetam in early-onset epileptic encephalopathy due to STXBP1 mutation. Brain Dev 2016;38:128-131.

41. Yamamoto T, Shimojima K, Yano T, et al. Loss-of-function mutations of STXBP1 in patients with epileptic encephalopathy. Brain Dev 2015.

42. Verhage M, Maia AS, Plomp JJ, et al. Synaptic assembly of the brain in the absence of neurotransmitter secretion. Science 2000;287:864-869.

43. Toonen RF, Wierda K, Sons MS, et al. Munc18-1 expression levels control synapse recovery by regulating readily releasable pool size. Proc Natl Acad Sci USA 2006;103: 18332-18337.

44. Nabbout R, Chemaly N, Chipaux M, et al. Encephalopathy in children with Dravet syndrome is not a pure consequence of epilepsy. Orphanet J Rare Dis 2013;8:176.

45. Fasano A, Borlot F, Lang AE, Andrade DM. Antecollis and levodopa-responsive parkinsonism are late features of Dravet syndrome. Neurology 2014;82:2250-2251.

46. Yamashita S, Chiyonobu T, Yoshida M, et al. Successful treatment with levetiracetam in a case of Ohtahara syndrome caused by STXBP1 mutation. No To Hattatsu 2013;45:64-66.

47. Lynch BA, Lambeng N, Nocka K, et al. The synaptic vesicle protein SV2A is the binding site for the antiepileptic drug levetiracetam. Proc Natl Acad Sci USA 2004;101: 9861-9866.

48. Hussain S. Developing a PPI inhibitor-based therapy for STXBP1 haploinsufficiency-associated epileptic disorders. Front Molecular Neuroscience 2014;7:6.

49. van Breevoort D, Snijders AP, Hellen N, et al. STXBP1 promotes Weibel-Palade body exocytosis through its interaction with the Rab27A effector Slp4-a. Blood 2014;123: 3185-3194. 


\section{Neurology}

\section{STXBP1 encephalopathy: A neurodevelopmental disorder including epilepsy}

Hannah Stamberger, Marina Nikanorova, Marjolein H. Willemsen, et al.

Neurology published online February 10, 2016

DOI 10.1212/WNL.0000000000002457

This information is current as of February 10, 2016

\section{Updated Information \& Services \\ Supplementary Material \\ Subspecialty Collections}

Permissions \& Licensing

Reprints including high resolution figures, can be found at: http://www.neurology.org/content/early/2016/02/10/WNL.0000000000 002457.full.html

Supplementary material can be found at: http://www.neurology.org/content/suppl/2016/02/11/WNL.000000000 0002457.DC1.html

This article, along with others on similar topics, appears in the following collection(s):

All Epilepsy/Seizures

http://www.neurology.org//cgi/collection/all_epilepsy_seizures

\section{All Genetics}

http://www.neurology.org//cgi/collection/all_genetics

\section{Autism}

http://www.neurology.org//cgi/collection/autism

Mental retardation

http://www.neurology.org//cgi/collection/mental_retardation

Information about reproducing this article in parts (figures,tables) or in its entirety can be found online at:

http://www.neurology.org/misc/about.xhtml\#permissions

Information about ordering reprints can be found online: http://www.neurology.org/misc/addir.xhtml\#reprintsus

Neurology ${ }^{\circledR}$ is the official journal of the American Academy of Neurology. Published continuously since 1951 , it is now a weekly with 48 issues per year. Copyright @ 2016 American Academy of Neurology. All rights reserved. Print ISSN: 0028-3878. Online ISSN: 1526-632X.

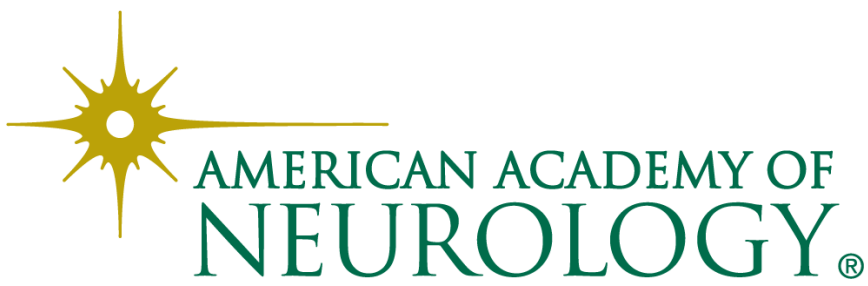

